\title{
Temperature memory effect in two-way shape memory TiNi and TiNiCu springs
}

\author{
H. J. YU, Z. G. WANG, X. T. ZU* \\ Department of Applied Physics, University of Electronic Science and Technology of China, \\ Chengdu 610054, People's Republic of China \\ E-mail: xiaotaozu@yahoo.com;xtzu@uestc.edu.cn
}

S. Z. YANG

School of Physics and Electronics Information, China West Normal University, Nanchong 637002, China

\author{
L. M. WANG \\ Department of Nuclear Engineering and Radiological Sciences, University of Michigan, Ann \\ Arbor MI 48109, USA
}

Published online: 12 April 2006

\begin{abstract}
An incomplete thermal cycle upon heating in a shape memory alloy (arrested at a temperature between $A_{s}$ and $A_{f}$ ) induced a kinetic stop in the next complete thermal cycle. The kinetic stop temperature is closely related to the previous arrested temperature. This phenomenon is named temperature memory effect (TME). In this article, the TME in two-way shape memory TiNiCu and TiNi springs was investigated by performing either a single incomplete cycle, or a sequence of incomplete cycles. $N$ points of temperatures could be memorized if $N$ times of incomplete cycles on heating were performed with different arrested temperatures in a decreasing order. The capability is enhanced by performing repetitive incomplete cycles with the same temperature, and the TME can be eliminated by appropriate complete transformation cycle. The TME is originated from the relaxation of both the strain energy between martensite and coherent strain between parent phase and martensite.

(C) 2006 Springer Science + Business Media, Inc.
\end{abstract}

\section{Introduction}

Shape memory alloys (SMAs) have been extensively studied in the past decades for their unique shape memory effect (SME) and superelasticity (SE) behavior in many applications, especially in SMAs based smart structures $[1,2]$. Besides the SME and SE, some research has also shown that SMAs have the ability to memory their thermal history [3, 4]. This phenomenon was defined as temperature memory effect (TME) [5]. If a reverse transformation of a SMA is arrested at a temperature between $A_{s}$ and $A_{f}$, a kinetic stop will appear in the next complete transformation cycle. The kinetic stop temperature is a "memory" of the previous arrested temperature $[5,6]$. It is a consequence of a partial reverse phase transformation due to an incomplete cycle on heating (ICH) with a low temperature limit below $M_{f}$ and a high temperature limit between $A_{s}$ and $A_{f}$. However, TME can also be erased through an appropriate thermal treatment [6]. The TME has been systemically investigated by Wang et al. [6] using differential scanning calorimetry (DSC).

In this article, the kinetic stops induced by in complete cycling in two-way shape memory $\mathrm{TiNi}$ and $\mathrm{TiNiCu}$ springs was investigated by performing either a single incomplete cycle, or a sequence of incomplete cycles with different arrested temperatures, or a sequence of repetitious incomplete cycles with same arrested temperatures to clarify the origin of the TME.

\section{Experimental}

The investigations have been carried out on commercial $\mathrm{TiNiCu}$ wire (diameter $=0.50 \mathrm{~mm}$ ) and TiNi (diameter $=0.50 \mathrm{~mm}$ ), provided by the Northwest Institute of Non-Ferrous Metal of China. Two-way shape memory springs were prepared with the following procedure [7]

*Author to whom all correspondence should be addressed. 


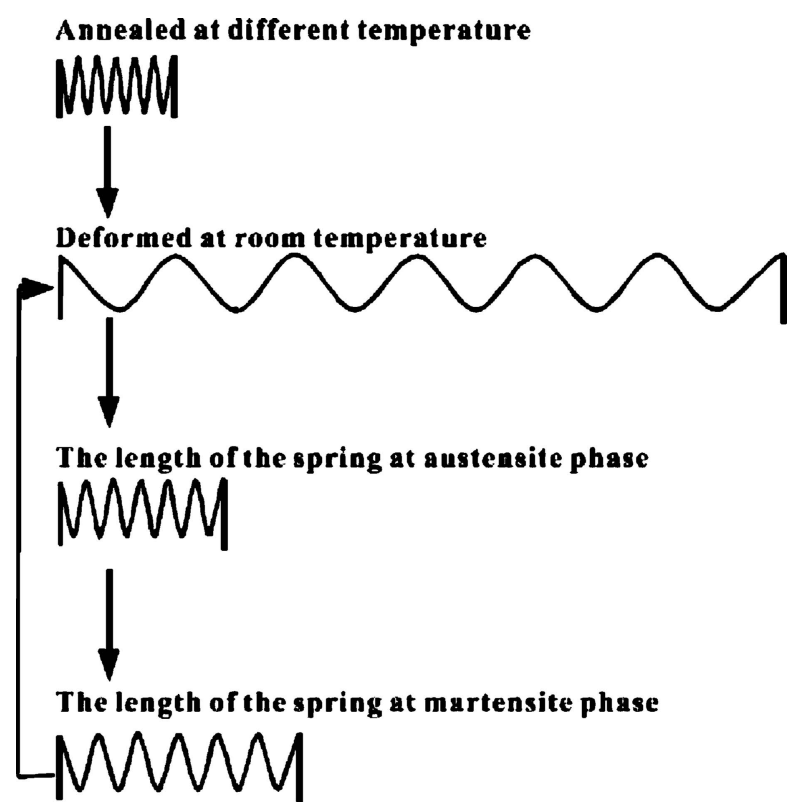

Figure 1 Schematic diagram for the thermomechanical training of the two-way shape memory springs [7].

(as shown in Fig. 1): the SMAs wires were wound on a cylindrical jig and annealed at $500^{\circ} \mathrm{C}$ for $1 \mathrm{~h}$ followed by air-cooling. The mean diameter of the spring is $6 \mathrm{~mm}$, the pitch of the spring is $0.1 \mathrm{~mm}$ after the annealing treatment.
The springs were trained: the springs were elongated till the pitch reached $12 \mathrm{~mm}$ at a temperature of $20^{\circ} \mathrm{C}$ (in martensitic state) before relaxing the force and heating up to $95^{\circ} \mathrm{C}$, a temperature slightly higher than the $A_{f}$. The spring contracted as a result of reverse martensitic transformation, then the springs was cooled to $20^{\circ} \mathrm{C}$ again, the above procedure was called one training cycle. The springs were thermal-mechanically trained for 30 cycles to gain two-way shape memory effect.

The contraction rate-temperature curves of the springs were determined. The heating/cooling rate is $2.5^{\circ} \mathrm{C} / \mathrm{min}$. The contraction rate $\eta$ is defined as $\eta=\left(\left(L_{M}-L_{A}\right) / L_{M}\right)$ $\times 100 \% . L_{M}$ and $L_{A}$ represent the length of the spring at martensite and austenite states, respectively. TME in TiNiCu spring was also investigated using differential scanning calorimetry (DSC) with a scanning rate of $10^{\circ} \mathrm{C} / \mathrm{min}$.

\section{Results}

\subsection{Temperature memory effect in TiNiCu spring}

The contraction rate-temperature curve of $\mathrm{TiNiCu}$ spring with a global transformation cycle is shown in Fig. 2a. The $A_{s}$ and $A_{f}$ are the start and finish temperatures of the reverse martensitic transformation, and $M_{s}$ and $M_{f}$ are those of martensitic transformation. The transforma-
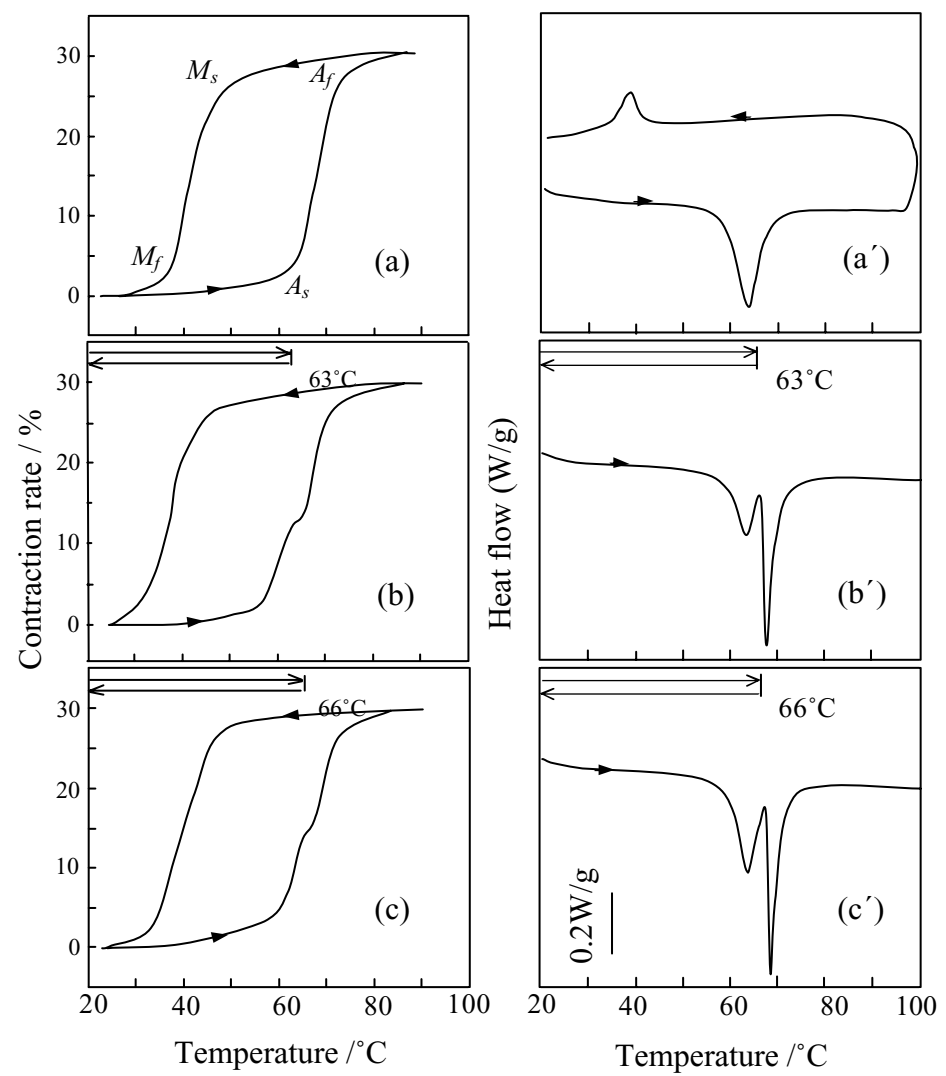

Figure 2 Contraction rate-temperature curve of TiNiCu spring with a global transformation cycle (a) and the TME of the same sample with single incomplete cycle on heating at $63(\mathrm{~b})$ and $66^{\circ} \mathrm{C}(\mathrm{c})$; DSC results of TiNiCu spring $\left(\mathrm{a}^{\prime}\right)$ and the TME of same sample with single incomplete cycle on heating at $63\left(\mathrm{~b}^{\prime}\right)$ and $66^{\circ} \mathrm{C}\left(\mathrm{c}^{\prime}\right)$. 
TABLE I Transformation temperatures for TiNi and TiNiCu springs heat-treatet $500^{\circ} \mathrm{C} \times 1 \mathrm{~h}$

\begin{tabular}{lllll}
\hline $\begin{array}{l}\text { Transformation } \\
\text { temperature }\end{array}$ & $A_{s}\left({ }^{\circ} \mathrm{C}\right)$ & $A_{f}\left({ }^{\circ} \mathrm{C}\right)$ & $M_{s}\left({ }^{\circ} \mathrm{C}\right)$ & $M_{f}\left({ }^{\circ} \mathrm{C}\right)$ \\
\hline TiN & 58 & 70.5 & 47.5 & 30.5 \\
TiNiCu & 60.5 & 73 & 49.5 & 35 \\
\hline
\end{tabular}

tion temperatures deduced from the curve are listed in Table I. The contraction rate-temperature curves of TiNiCu springs with single incomplete cycle upon heating at $T_{s}=63$ and $66^{\circ} \mathrm{C}$, respectively, are shown in Fig. $2 \mathrm{~b}$ and $\mathrm{c}$, the plateaus are clearly observed on the contraction rate-temperature curves upon heating. Figs $2 b^{\prime}$ and $c^{\prime}$ show the DSC results of TiNiCu spring after performing an incomplete cycle at a temperature between $A_{s}$ and $A_{f}$ upon heating. The stop temperatures are identical to that of Figs $2 b$ and $c$.

Fig. 3a shows the results of TiNiCu springs after performing two successive incomplete cycles with decreasing order upon heating at temperatures of 68 and $63^{\circ} \mathrm{C}$, and two plateaus are observed corresponding to the two arrested temperatures. Fig. $3 \mathrm{~b}$ shows the results of $\mathrm{TiNiCu}$ springs after performing two successive incomplete cycles upon heating at temperatures of 63 and $68^{\circ} \mathrm{C}$ with increasing order. While only a plateau can be observed from Fig. 3b, and the maximum temperature of $T_{s}=68^{\circ} \mathrm{C}$ is memorized. The phenomenon shows that only the highest temperature of the two temperatures (with increasing order) is memorized, which implies that further heating to a temperature exceeding the previous stop temperature can wipe out the temperature memory effect caused by the previous stop temperature. If a number $N$ of incomplete cycles on heating with different arrested temperatures is performed in a decreasing order, $N$ plateaus can be found. The TME is a reversible process, and from Fig. $3 \mathrm{c}$ it can be noticed that the plateaus of the global transformation (Figs $3 \mathrm{a}$ and $\mathrm{b}$ are completely eliminated in the following complete cycle. The above results are confirmed by the DSC results shown in Figs $3 a^{\prime}-c^{\prime}$.

\subsection{Temperature memory effect in shape memory TiNi spring}

Fig. 4a shows the contraction rate-temperature curve of TiNi spring upon heating and cooling. There is no plateau as shown in Fig. 4a The transformation temperatures $A_{s}$, $A_{f}, M_{s}$ and $M_{f}$ deduced from the curves are listed in Table I. Figs $4 \mathrm{~b}$ and c show temperature memory effects of TiNi spring in one single incomplete cycle upon heating
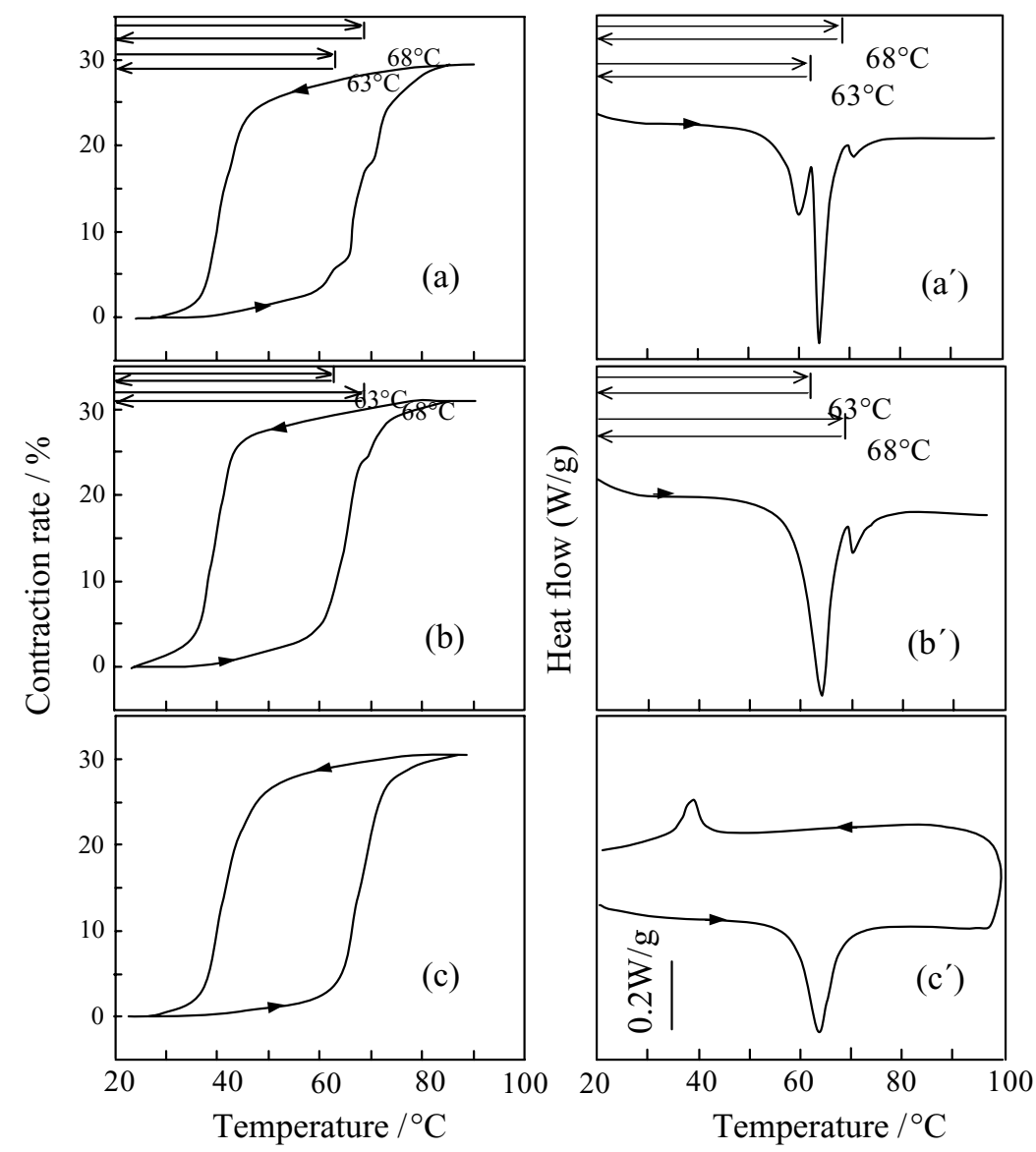

Figure 3 Contraction rate -temperature curve of TiNiCu spring with two incomplete cycle at $T_{s}=68$ and $63^{\circ} \mathrm{C}$ with decreasing order (a), $T_{s}=63$ and $68^{\circ} \mathrm{C}$ with increasing order (b) and subsequent global transformation (c); DSC results of TiNiCu spring with two stops at $T_{s}=68$ and $63^{\circ} \mathrm{C}$ with decreasing order Fig. $\mathrm{a}^{\prime}, T_{s}=63$ and $68^{\circ} \mathrm{C}$ with increasing order $\left(\mathrm{b}^{\prime}\right)$ and DSC results of subsequent global transformation $\left(\mathrm{c}^{\prime}\right)$. 


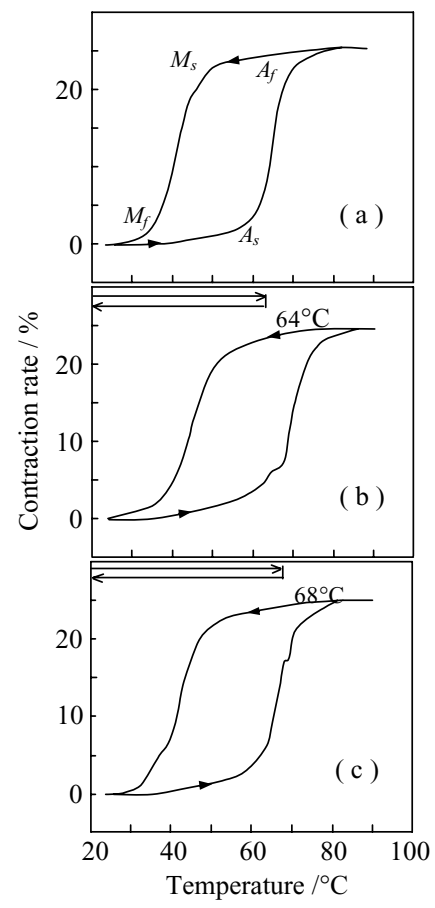

Figure 4 Contraction rate-temperature curve of TiNi spring with a global transformation cycle (a) and the TME of same sample with single incomplete cycle on heating at $64(\mathrm{~b})$ and $68^{\circ} \mathrm{C}(\mathrm{c})$.

at the stop temperatures $T_{s}=68$ and $64^{\circ} \mathrm{C}$, respectively. A plateau, corresponding to the arrested temperatures, can clearly be observed for each contraction rate-temperature curve. Fig. 5a shows the results of two-way shape memory TiNi spring performed with two successive incomplete transformation cycles upon heating at the temperatures $T_{s}$ $=68$ and $64^{\circ} \mathrm{C}$ with decreasing order, and two plateaus can be clearly observed in the curve. Fig. $5 \mathrm{~b}$ gives the results of TiNi spring by performing two successive incomplete cycles upon heating at $T_{s}=64$ and $68^{\circ} \mathrm{C}$ (with increasing order). Only a plateau can be clearly found in the curve, and the maximum temperature of $T_{s}=68^{\circ} \mathrm{C}$ is memorized. The temperature memory effect can be easily wiped out by the following complete thermal cycle as revealed from Fig. 5c.

\subsection{Effect of number of incomplete transformation cycles on TME}

For practical applications, the two-way shape memory springs are often used many thermal cycles. It is necessary to study the repeatability of TME after many incomplete thermal cycles. Fig. 6a shows the rensults of TiNi spring after performing 1, 60 and 120 incomplete cycles upon heating at the temperature $T_{s}=65^{\circ} \mathrm{C}$ and Fig. $6 \mathrm{~b}$ also shows the contraction rate-temperature curves of TiNiCu spring by performing 1, 60 and 120 incomplete cycles upon heating at the temperature of $65^{\circ} \mathrm{C}$. With increasing number of incomplete cycle, the plateau is widened toward to high temperature as shown in Fig. 6 and Fig. 7.

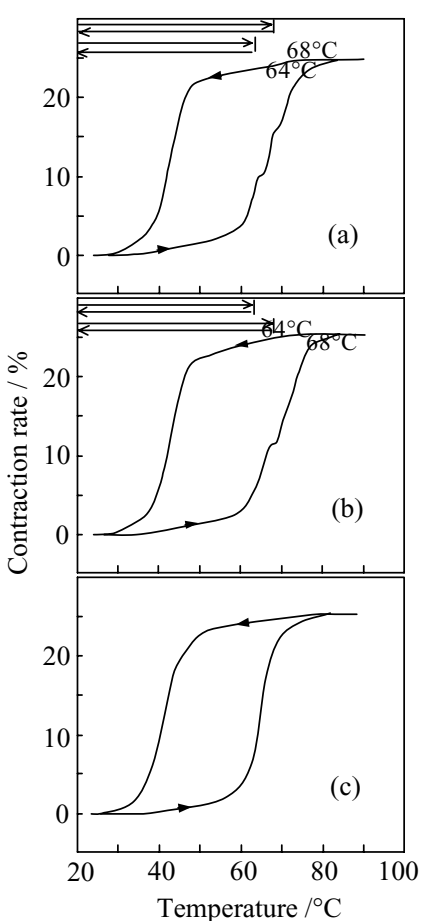

Figure 5 Contraction rate-temperature curve showing the temperature memory effect of TiNi spring with three single plateaus at $T_{s}=68$ and $64^{\circ} \mathrm{C}$ with decreasing order (a), $T_{s}=64$ and $68^{\circ} \mathrm{C}$ with increasing order (b) and subsequent global transformation (c).
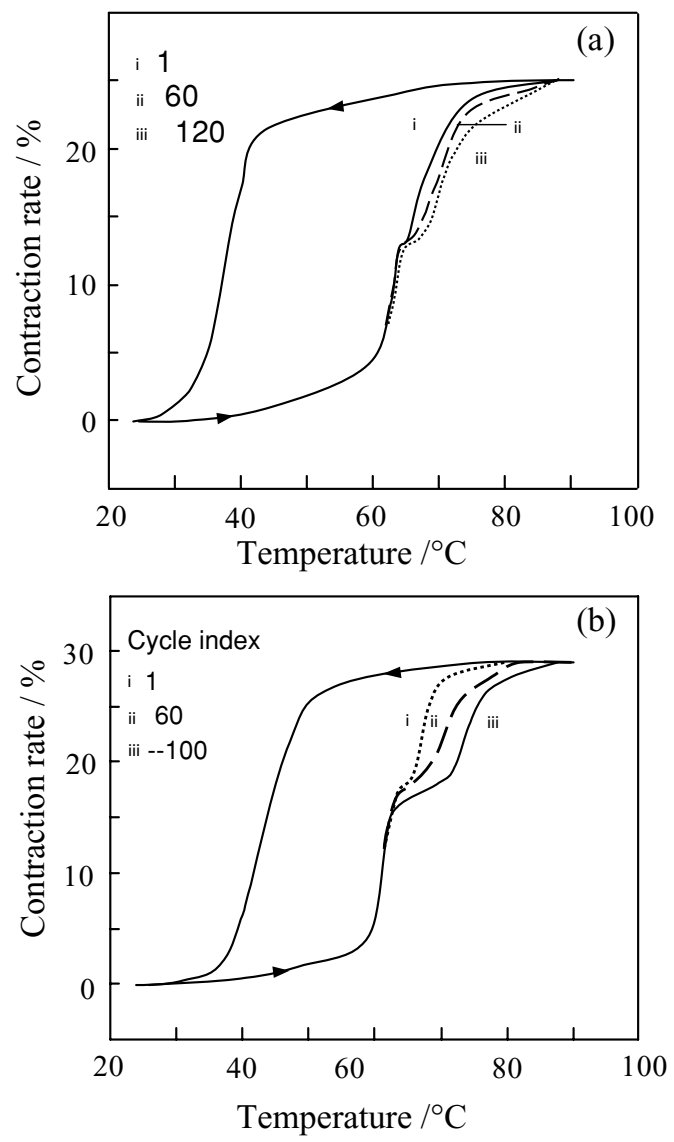

Figure 6 The temperature memory effect of the 1st, 60th and 120th working cycles at $T_{s}=65^{\circ} \mathrm{C}$ in (a) TiNi spring and (b) TiNiCu spring. 


\section{Discussion}

The temperature memory effect is a common phenomenon in shape memory alloy, which is induced by a partial reverse transformation [6]. In the article, the temperature memory effect performed on two-way shape memory $\mathrm{TiNi}$ and $\mathrm{TiNiCu}$ springs revealed clearly TME is one of the significant characteristics for two-way shape memory springs. If a number $N$ of ICHs with different arrested temperatures is performed with decreasing order, $N$ temperatures can be memorized. The capability to memory temperature is enhanced by performing repetitious incomplete cycles with same temperature, and can be eliminated by appropriate complete transformation heat cycle. During the partial reverse transformation, the martensite to austenite transformation is stopped at a certain temperature between $A_{s}$ and $A_{f}$, and only part of the martensite transforms into the parent phase, with the rest of the martensite remaining. Here the remaining martensite is called M1. With further decreasing the temperature below $M_{f}$, the parent phase transforms back to martensite, and the newly formed martensite is called M2. During the following heating process, M2 and M1 transform into the parent phase sequentially, causing a plateau between these transformations. Some researchers explained the temperature memory effect using the release of elastic strain energy, which serves as driving force during the reverse transformation [8]. Madangopal et al. [9] proposed that M2 could store more elastic strain energy than M1 in a global transformation, therefore the reverse transformation of M2 could be somehow prepositioned. However, Airoldi [4] explained the temperature memory effect using the lack of elastic strain energy in M2, therefore a higher temperature is necessary to start the transformation of M1, after the transformation of M2 finishes.

Martensitic transformation in shape memory alloy occurs between austenite and martensite. During the transformation from austenite (B2) to martensite, some elastic strain energy is stored in the thermoelastic martensite variants. The coherent energy resulted from the lattice distortions at the coherent interfaces of the adjacent phases has a prominent effect on the transformation characteristics [10, 11]. The TME should not be only attributed to the release of the elastic strain energy stored in the martensite variants, and the coherent energy of the adjacent phases also contributes to the TME. While the M1 and M2 have different orientation structures and different elastic energies between martensitic variants, which cause the different transformation temperatures of M1 and M2 into austenite during the next heating process. More mircrostructure experiments are needed to confirm the above-proposed mechanism for the TME.

\section{Conclusions}

In this article, the TME induced by incomplete cycling in two way shape memory $\mathrm{TiNi}$ and $\mathrm{TiNiCu}$ spring was investigated by performing either a single incomplete cycle, or a sequence of repetitious incomplete cycles with same arrested temperatures. The results indicate that TME is special characteristic in shape memory alloy, which is induced by a partial reverse transformation. It can be concluded that the TME is originated from the relaxation of both the elastic energy between martensite variants and coherent strain energy between parent phase and martensite.

\section{Acknowledgments}

This study was supported financially by the National Natural Science Foundation of China (10175042) and by the Program for New Century Excellent Talents in University(NCET-04-0899) and the Ph.D. Funding Support Program of Education Ministry of China (20050614013) and by the Sichuan Young Scientists Foundation (03ZQ026-059).

\section{References}

1. Z. G. WEI and R. SAndstrom, J. Mater. Sci. 33 (1998) 3743.

2. Z. G. WEI, R. SANDSTROM and S. MIYAZAKI, ibid. 33 (1998) 3763.

3. G. AIROLDI and G. RIVA, Key Eng. Mater. 48 (1990) 5.

4. G. Airoldi, A. CORSI and R. Riva, Mater. Sci. Eng. A 241 (1998) 233.

5. Y. J. ZHENG, L. S. CUI and J. SChrooten, Appl. Phy. Lett. 84 (2004) 31.

6. Z. G. WANG, X. T. ZU, Y. Q. FU and L. M. WANG, Thermochimica Acta 428 (2005) 199.

7. Z. G. WANG, X. T. ZU, X. D. FENG and J. Y. DAI, Mater. Lett. 54(1) (2002) 55.

8. Z. Y. XU, "Martensite and Matensite Transformation" (Science Press, China, 1999) p. 59.

9. K. MADANGOPAL, S. BAnERJEE and S. LEle, Acta Metall. Mater. 42 (1994) 1875.

10. Y. HUO and X. ZU, Continuum Mech. Thermodyn. 10 (1998) 179.

11. Z. G. WANG, X. T. ZU, X. D. FENG, L. B. LIN, S. ZHU, L. P. YOU and L. M. WANG, Material Science \& Engineering A 345 (2003) 249.

Received 4 June 2004

and accepted 27 July 2005 